\title{
Carbon Emission Disclosure: Studi pada Perusahaan Manufaktur Indonesia
}

\author{
Irwhantoko' ${ }^{1 *}$, Basuki ${ }^{1}$ \\ ${ }^{1}$ Fakultas Ekonomi dan Bisnis Universitas Airlangga Surabaya \\ Jl. Airlangga No. 4-6, Surabaya 60286 \\ *Penulis korespondensi, E-mail: Irwhantoko@gmail.com
}

\begin{abstract}
ABSTRAK
Penelitian ini bertujuan untuk menguji faktor-faktor yang berpengaruh terhadap pengungkapan emisi karbon. Faktor yang diuji di dalam penelitian ini meliputi ukuran perusahaan, profitabilitas, kompetisi, pertumbuhan, rasio utang pada ekuitas, dan reputasi Kantor Akuntan Publik. Metode yang digunakan untuk mengukur seberapa luas pengungkapan emisi karbon mengadopsi dari check list yang dikembangkan berdasarkan lembar permintaan yang diperoleh dari Carbon Disclosure Project (CDP). Sampel penelitian ini dipilih menggunakan purposive sampling dan terseleksi 19 perusahaan pemanufakturan yang lterdaftar di Bursa Efek Indonesia berturut-turut mulai dari tahun 2012- 2013. Hasil penelitian ini menunjukan bahwa rasio utang pada ekuitas berpengaruh negatif signifikan pada pengungkapan emisi karbon, sementara faktor lainnya tidak berpengaruh signifikan.
\end{abstract}

Kata kunci: Emisi Karbon, Gas Rumah Kaca, Pemanasan global, Pengungkapan Sukarela, Protokol kyoto.

\begin{abstract}
The objective of this study is to examine factors that influence the carbon emission disclosure. Several factors, such as size, profitability, competition, growth, debt to equity ratio, and public accountant firm are included in this study. We adopt the checklist issued by Carbon Disclosure Project (CDP) to measure to what extent the carbon emission disclosures is made. This research applied purposive sampling method to obtain 19 listed manufacturing business in the Indonesian Stock exchange for the period 2012 to 2013. The results show that debt to equity ratio have significant negative correlation with carbon emission disclosure, however other factors cannot be proved as the determinan of carbon emission disclosure.
\end{abstract}

\section{Keywords: Carbon emission, Greenhouse gas, Global warming, Kyoto Protocol, Voluntary} disclosure.

\section{PENDAHULUAN}

Komitmen politik internasional yang telah disepakati secara universal di Rio de Janerio, Brazil, Juni 1992 telah menciptakan sebuah gagasan era ekonomi baru. Gagasan yang dibentuk melalui KTT Bumi (Earth Summit) tersebut bertujuan untuk mewujudkan konsep pembangunan ekonomi berkelanjutan yaitu pembangunan yang memenuhi kebutuhan generasi saat ini tanpa mengorbankan kepentingan generasi-generasi selanjutnya. Kesepakatan terhadap komitmen tersebut dilatarbelakangi oleh kesadaran bahwa pembangunan yang hanya berusaha mencapai pertumbuhan ekonomi setinggi-tingginya justru akan menghambat keberlanjutan pertumbuhan pembangunan itu sendiri. Seperti perubahan iklim dan pemanasan global dapat merusak material bahan baku akibat banjir, sistem distribusi terhambat akibat tanah longsor, dan berbagai kerusakan karena faktor lain yang terkait dengan rantai nilai (value chain) pendukung kelangsungan hidup perusahaan. Untuk mencegah kerugian ekonomi lebih besar, United Nation Framework Convention on Climate Change (UNFCCC) menciptakan sebuah amandemen Internasional yang dikenal dengan Protokol Kyoto. Protokol Kyoto merupakan sebuah konvensi internasional yang 
dibuat di Kyoto, Jepang pada tahun 1997. Esensi dari konvensi tersebut ialah mewajibkan anggota Anex 1 mengurangi emisi gas rumah kaca (GRK), karena perubahan iklim yang terjadi akhir-akhir ini disebabkan oleh akumulasi penggunaan energi fosil semenjak revolusi industri tahun 1850. Gas yang dikatagorikan sebagai GRK adalah Carbon dioxide $\left(\mathrm{CO}_{2}\right)$, Methane $\left(\mathrm{CH}_{4}\right)$, Nitrous oxide $\left(\mathrm{N}_{2} \mathrm{O}\right)$, Hydrofluorocarbons (HFCS), Perfluorocarbons (PFCS), dan Sulfur hexafluoride $\left(\mathrm{SF}_{6}\right)$.

Pada periode pertama Protokol Kyoto, 39 negara industri maju dalam kelompok negara Anex 1 berkomitmen memangkas emisi gas rumah kaca secara relatif agar kembali pada keadaan level 5 persen dari dasar laporan tingkat emisi tahun 1990. Pada periode ini pengurangan emisi GRK harus dicapai dihitung mulai tahun 2008 dan berakhir pada tahun 2012. Terciptanya komitmen tersebut merupakan upaya untuk mengendalikan level konsentrasi emisi GRK di atmosfer agar suhu rata-rata permukaan bumi tidak melebihi batas maksimal 2 derajat celsius dari jaman pra industri.

Protokol Kyoto mengatur tiga mekanisme dalam mengurangi emisi GRK. Tiga mekanisme tersebut adalah Clean Development Mechanism (CDM), Joint Implementation (JI), dan Emission Trading (United Nations Framework Convention on Climate Change (UNFCCC), 1998). CDM dijelaskan pada pasal 12, yaitu anggota non Annex 1 dapat membantu anggota Annex 1 mencapai pemenuhan batas emisi melalui pembangunan sebuah proyek pengurangan emisi. Partisipasi pada proyek bersifat sukarela, tetapi partisipan akan diuntungkan oleh hasil pengurangan emisi yang tersertifikasi/Certified Emission Reduction (CER) karena akan bernilai ekonomis dan dapat digunakan oleh anggota Annex 1 dalam memenuhi komitmentya pada batas emisi.

Kedua, Joint Implementation (JI) dijelaskan pada pasal 6, bahwa antar anggota Annex 1 dapat bekerjasama dalam mengurangi atau membatasi emisi GRK agar tidak melebihi dari batas komitmen yang telah ditetapkan. Kerjasama tersebut membolehkan setiap anggota mentransfer atau menerima tiap unit penurunan emisi yang dihasilkan oleh proyek pengurangan emisi pada setiap sektor ekonomi.

Ketiga, Emission Trading dijelaskan pada pasal 17, bahwa diantara angota Annex 1 diperbolehkan melakukan perdagangan emisi. Perusahaan yang terbukti menghasilkan emisi dibawah batas yang diijinkan, hak pengeluaran emisi dapat diperdagangkan kepada perusahaan yang menghasilkan lebih banyak emisi. Sebalik- nya, jika perusahaan menghasilkan emisi melebihi target, mereka dapat membeli 'carbon credit' dari perusahaan dengan emisi dibawah target. 'Carbon credit' adalah sertifikat yang memberikan hak untuk mengeluarkan satu ton karbondioksida atau gas rumah kaca lainnya yang ekuivalen dengan satu ton karbondioksida.

Indonesia meratifikasi Protokol Kyoto periode pertama pada 28 Juni 2004 melalui UndangUndang No. 17 Tahun 2004. Indonesia sebagai negara berkembang tidak berkewajiban menurunkan emisi, tetapi partisipasinya sangat diperlukan untuk mencapai tujuan UNFCCC serta diharapkan mampu menjembatani peran negara maju dalam membangun berbagai sektor pengurangan emisi dan meningkatkan penyerapan emisi karbon melalui investasi.

Pada periode kedua Protokol Kyoto diadakan di Doha, Qatar pada 8 Desember 2012. Konvensi tersebut menghasilkan target baru yaitu anggota Annex 1 diwajibkan mengurangi emisi GRK sebesar 18 persen dari dasar emisi tahun 1990 yang dapat dicapai selama 8 tahun, dimulai dari tahun 2013 hingga 2020 (United Nations Framework Convention on Climate Change (UNFCCC), 2012). Indonesia meratifikasi Protokol Kyoto periode kedua pada 30 September 2014.

Implikasi dari Protokol Kyoto memunculkan carbon accounting, yang merupakan keharusan perusahaan untuk melakukan pengakuan, pengukuran, pencatatan, penyajian dan pengungkapan emisi karbon. Lebih lanjut Ratnatunga (2007) menyatakan bahwa akuntansi karbon berkaitan dengan efisiensi emisi karbon pada penggunaan bahan baku, biaya tenaga kerja, biaya overhead pabrik, biaya overhead lingkungan dan biaya terkait dengan manajemen standar karbon. Sementara ini praktik pengungkapan emisi karbon di Indonesia masih voluntary disclosure. Beberapa acuan yang digunakan dalam penghitungan emisi karbon oleh perusahaan Indonesia mengacu pada ketentuan protokol $\mathrm{CO}_{2}$ yang diadopsi dari World Business Council for Sustainable Development/World Resources Institute (WBCSD-WRI) dan standar yang dikeluarkan oleh United Nation Environtment Progamme (UNEP).

Choi et al. (2013) meneliti faktor-faktor yang memengaruhi pengungkapan emisi karbon (Carbon Emission Disclosure). Pengukuran emisi karbon yang digunakan adalah check list yang diperoleh dari CDP (Carbon Disclosure Project). Choi et al. (2013) menggunakan variabel independen Ukuran perusahaan, Profitabilitas, Tingkat Emisi Karbon, Tipe Industri, dan Kualitas Corporate Governance. Berdasarkan penelitian ter- 
sebut, dilakukan pengujian lebih lanjut mengenai faktor-faktor yang mempengaruhi pengungkapan emisi karbon pada perusahan manufaktur di Indonesia.

Penelitian ini betujuan untuk menguji faktorfaktor yang mempengaruhi pengungkapan emisi karbon (Carbon Emission Disclosure) pada perusahaan manufaktur di Indonesia, yang meliputi ukuran perusahaan, profitabilitas, kompetisi, pertumbuhan, rasio utang pada ekuitas, dan reputasi kantor akuntan publik.

Teori yang digunakan sebagai dasar pengungkapan emisi karbon di dalam penelitian ini adalah teori legitimasi. Teori legitimasi berfokus pada hubungan antara perusahaan dan masyarakat melalui peraturan yang dibuat oleh pemerintah. Sebagaimana yang telah ditekankan oleh Gray et al. (1996) bahwa pengungkapan berperan dalam menjembatani perusahaan dengan kelompok masyarakat. Perusahaan terdorong untuk mendapatkan legitimasi dari masyarakat karena ingin meyakinkan bahwa aktifitas operasi perusahaan telah sesuai dengan norma dan batasanbatasan berdasarkan pada ketentuan yang berlaku (Deegan dan Unerman, 2006). Legitimasi itu sendiri akan diperoleh perusahaan jika antara perusahaan dan masyarakat terdapat persamaan hasil yang diharapkan, sehingga akan mengurangi risiko jangka panjang atas adanya tuntutan dari masyarakat (Deegan et al., 2002). Hal tersebut disebabkan adanya kontrak sosial antara perusahaan dengan masyarakat yang memberikan otoritas untuk menggunakan sumber daya ekonomi (Ghozali dan Chariri, 2007). Ketika terdapat perbedaan antara perusahan dengan masyarakat terkait dengan nilai yang dianut "legitimation gap", maka pada saat itu legitimasi perusahaan berada pada posisi terancam dan mampu mempengaruhi kemampuan perusahaan untuk melanjutkan kegiatan usahanya. Ancaman terbesarnya ialah masyarakat akan mencabut kontrak sosialnya ketika mereka merasa tidak puas atas aktivitas perusahaan.

Dalam rangka menghindari akibat diatas pemerintah Indonesia meratifikasi Protokol Kyoto periode pertama melalui Undang Undang No. 17 tahun 2004, dan memperpanjang komitmen periode kedua pada 30 September 2014. Mengesahkan Peraturan Presiden No. 61 Tahun 2011 mengenai Rencana Aksi Nasional Penurunan Emisi Gas Rumah Kaca (RAN-GRK) untuk mendukung penurunan tingkat emisi 26 persen dengan usaha sendiri, atau penurunan 41 persen dengan kerjasama internasional sampai tahun
2020 tanpa ada rencana aksi (bussines as usual/BAU) pada sektor pertanian, kehutanan dan lahan gambut, energi dan transportasi, industri, pengolahan limbah dan kegitan pendukung lainnya. Tindakan yang telah dilakukan pemerintah diatas merupakan alat penggerak industri untuk merespon tekanan lingkungan dengan mereduksi konsentrasi emisi gas rumah kaca pada tingkat tertentu. Berbagai upaya penurunan emisi GRK yang telah dilakukan oleh pelaku usaha dapat ditunjukan melalui pengungkapan emisi karbon (Carbon Emission Disclosure).

\section{Pengaruh Ukuran Perusahaan terhadap Carbon Emission Disclosure}

Sumber daya yang dimiliki perusahaan dapat tercermin dari ukuranya. Semakin besar ukuran perusahaan semakin besar sumber daya yang dimiliki (Choi et al., 2013). Ukuran perusahaan juga dapat menggambarkan jumlah aktifitas operasional. Perusahaan yang berukuran lebih besar tentu memiliki lebih banyak aktifitas. Segala aktifitas operasional perusahaan tidak jarang berhubungan langsung dengan lingkungan. Sehingga disamping perusahaan menjalankan operasionalnya perusahaan juga perlu menjaga kelestarian lingkungan demi mendukung kinerjanya. Masyarakat akan memberikan tekanan kepada perusahaan ketika ada kegiatan perusahaan yang langsung berdampak pada lingkungan tidak sesuai dengan norma yang telah ditetapkan. Sebagai tindak respon terhadap tekanan masyarakat, perusahaan melakukan pengungkapan terkait kinerjanya. Perusahaan yang memiliki sumber daya lebih besar akan lebih mampu dan lebih cepat menyadiakan informasi pada pihak eksternal. Sehingga antara perusahaan besar dengan perusahaan kecil potensi untuk menyediakan pengungkapan emisi karbon lebih mungkin dilakukan oleh perusahaan berukuran besar. Hasil penelitian, Stanny dan Ely (2008), PradoLorenzo et al. (2009), Luo et al. (2010), Tang dan Luo (2011), Gallego-Álvarez (2010), Borghei-Ghomi dan Leung (2013), Choi et al. (2013), Eleftheriadis dan Anagnostopoulou (2014), dan Jannah dan Muid (2014) menemukan bahwa ukuran perusahaan berpengaruh signifikan positif pada pengungkapan emisi karbon. Berdasarkan pada penjelasan di atas, maka dapat dihipotesiskan sebagai berikut.

$\mathrm{H}_{1}$ : Ukuran perusahaan berpengaruh positif pada Carbon Emission Disclosure. 


\section{Pengaruh Profitabilitas terhadap Carbon Emission Disclosure}

Kontribusi dalam menjaga keberlanjutan lingkungan seperti mengganti mesin-mesin produksi ramah lingkungan, ikut dalam kegiatan penanaman pohon, berusaha mengurangi emisi dan melakukan pengungkapan akan lebih mungkin dilakukan oleh perusahaan dengan kinerja lebih baik, sebab pengungkapan lingkungan membutuhkan sumber daya lebih besar. Walaupun pengungkapan lingkungan masih merupakan pengungkapan sukarela tetapi perusahaan dengan kinerja lebih baik akan lebih mampu melakukannya, dan semakin detil area pengungkapanya (Roberts, 1992). Argumen tersebut didukung hasil temuan Horváthová (2010) bahwa berdasarkan pada penelitian meta analisis dari 64 hasil penelitian yang dimulai dari tahun 1978 hingga 2008 menunjukan pengaruh antara kinerja lingkungan dengan kinerja ekonomi positif $55 \%$, negatif $15 \%$, dan sisanya $30 \%$ tidak memiliki pengaruh. Jannah dan Muid (2014) juga menemukan bahwa profitabilitas yang tinggi mampu meningkatkan kecenderungan pengungkapan informasi emisi karbon. Berdasarkan uraian diatas maka dihipotesiskan sebagai berikut.

$\mathrm{H}_{2}$ : Profitabilitas perusahaan berpengaruh positif Carbon Emission Disclosure.

\section{Pengaruh Kompetisi terhadap Carbon Emis- sion Disclosure}

Kompetisi yang ketat mampu menciptakan tekanan pada perusahaan lain yang berada pada industri yang sama. Peng et al. (2014) menganggap pengungkapan emisi karbon merupakan salah satu bentuk tekanan perusahaan pada lingkungan yang kompeten. Keadaan lingkungan industri dengan tingkat kompetisi yang tinggi mungkin akan memaksa perusahaan lain melakukan pengungkapan emisi karbon untuk ikut masuk ke jajaran perusahaan kompetitif (March, 1981). Sehingga jika perusahan kurang kompeten memaksakan berkompetisi dengan perusahan lebih kompeten melalui pengungkapan emisi, perusahaan tersebut akan lebih terbebani dengan biaya pengungkapan.

Pengungkapan emisi pada lingkungan bisnis yang kompetitif disebabkan oleh anggapan bahwa produk yang dirasa berhubungan dengan ekologi lebih baik dan sebaliknya. Persepsi seperti ini akan meningkatkan willingnes to pay pada produk, terutama memengaruhi preferensi konsumen dalam menentukan pembelian produk kebutuhan sehari- hari (Zhao dan Zhong, 2015). Dengan anggapan produk lebih ramah lingkungan lebih bernilai dari pada produk yang tidak ramah lingkungan, perusahaan dapat menciptakan keunggulan kompetitif. Atas dasar pertimbangan tersebut, dirumuskan hipotesis sebagai berikut.

$\mathrm{H}_{3}$ : Kompetisi berpengaruh positif pada Carbon Emission Disclosure.

\section{Pengaruh Pertumbuhan terhadap Carbon Emission Disclosure}

Perusahaan yang berada pada kondisi tumbuh akan lebih konserfatif dalam memanfaatkan sumber daya yang dimiliki. Perusahaan akan memanfaaatkan sumber daya dengan memfokuskannya pada peningkatan kinerja dan pengembangan pada sektor ekonomi. Perusahaan yang memiliki kesempatan tumbuh lebih tinggi lebih memprioritaskan tujuan ekonomi dibanding mempertimbangkan kelestarian lingkungan (PradoLorenzo et al., 2009). Maka kondisi seperti itu akan menciptakan kontradiksi antara penggerak pertumbuhan ekonomi dengan pengungkapan emisi karbon. Long et al. (2015) menyatakan bahwa terdapat hubungan dua arah antara Produk Domestik Bruto (PDB) dengan emisi karbon, batu bara, gas, dan konsumsi listrik. Penggunaan energi yang bersumber dari batu bara, gas memang berkorelasi dengan pertumbuhan ekonomi, akan tetapi ketika dibandingkan dengan menggunakan energy baru terbarukan hasilnya lebih kuat berkorelasi dengan peningkatan emisi karbon. Hasil penelitian Luo et al. (2013) menunjukan bahwa terdapat korelasi negatif antara pertumbuhan dengan pengungkapan karbon. Atas dasar pertimbangan tersebut, dirumuskan hipotesis.

H4: Pertumbuhan berpengaruh negatif pada Carbon Emission Disclosure.

\section{Pengaruh Rasio Utang pada Ekuitas ter- hadap Carbon Emission Disclosure}

Solvabilitas suatu perusahaan menunjukkan kemampuan perusahaan untuk memenuhi kewajiban financial-nya baik jangka pendek maupun jangka panjang. Semakin tinggi rasio semakin kurang baik bagi perusahaan (Sartono, 2001). Karena perusahaan yang memiliki komposisi modal lebih banyak bersumber dari utang berisiko mengalami kebangkrutan jika gagal melunasinya pada saat jatuh tempo. Untuk menghindari hal demikian, manajemen mengungkapkan informasi lebih luas kepada kreditur agar mereka tetap 
memahami kinerja perusahaan. Jika perusahaan menghindari kebijakan pengungkapan lebih detil, maka investor dan kreditor akan kesulitan untuk melakukan evaluasi pada kinerja perusahaan. Akibatnya, investor dan kreditor mungkin akan menunda investasi pada perusahaan tersebut. Freedman dan Jaggi (2005) menyatakan bahwa risiko penyebab kegagalan utang yang sedang dicoba untuk diungkapkan kepada kreditur ialah risiko perubahan iklim. Sehingga hal ini dapat diartikan bahwa pengungkapan emisi karbon merupakan cara perusahaan mengendalikan risiko kegagalan utang yang diakibatkan oleh besarnya kewajiban perusahaan. Menurut hasil temuan D'Amico et al. (2014) terdapat korelasi positif antara leverage (diukur dengan membandingkan utang dan ekuitas) dengan pengungkapan lingkungan. Atas dasar pertimbangan tersebut, dirumuskan hipotesis sebagai berikut.

$\mathrm{H}_{5}$ : Rasio utang pada ekuitas berpengaruh positif pada Carbon Emission Disclosure.

\section{Pengaruh Reputasi Kantor Akuntan Publik terhadap Carbon Emission Disclosure}

Pengungkapan informasi seluas luasnya disebabkan oleh harapan perusahan mendapatkan opini wajar tanpa pengecualian, sehingga biaya yang dikeluarkan untuk perikatan awal dapat dimanfaatkan secara maksimal (Watts dan Zimmerman, 1986). Mendapatkan opini wajar tanpa pengecualian menandakan bahwa laporan keuangan berkualitas tinggi dan akan menciptakan sinyal lebih positif jika diperoleh dari Kantor Akuntan berkualitas (Titman dan Trueman, 1986). Tingginya kredibilitas yang dimiliki oleh Kantor Akuntan Publik berkualitas membuatnya memiliki jumlah klien bisnis lebih banyak. Sehingga ketika auditor mempertanyakan hal-hal yang lebih luas, Kantor Akuntan Publik tidak akan merasa akan terjadi konflik kepentingan yang akan memperburuk hubunganya dengan klien (Ahmad et al., 2003). Menurut Craswell dan Taylor (1992) perusahaan yang diaudit oleh Kantor Akuntan Publik besar akan cenderung melakukan pengungkapan lebih luas yang bertujan untuk menyediakan lebih banyak informasi kepada auditor. Variabel ini diukur dengan menggunakan variabel dummy. Memberikan nilai 1 untuk KAP yang tergabung dalam skala besar (Big Four), dan 0 untuk KAP lainnya. Atas dasar pertimbangan tersebut penelitian ini menghipotesiskan

$\mathrm{H}_{6}$ : Reputasi Kantor Akuntan Publik Big Four berpengaruh positif pada Carbon Emission Disclosure.

\section{METODE PENELITIAN}

\section{Model Analisis}

Model yang digunakan untuk menguji hipotesis adalah sebagai berikut:

$$
\begin{aligned}
\text { CE_Disc }= & \alpha+B_{1} \text { Size }+B_{2} \text { Pro }+B_{3} \text { Com }+B_{4} \text { Grow }+ \\
& B_{5} \text { DER }+B_{6} \mathrm{KAP}+e
\end{aligned}
$$

Keterangan:

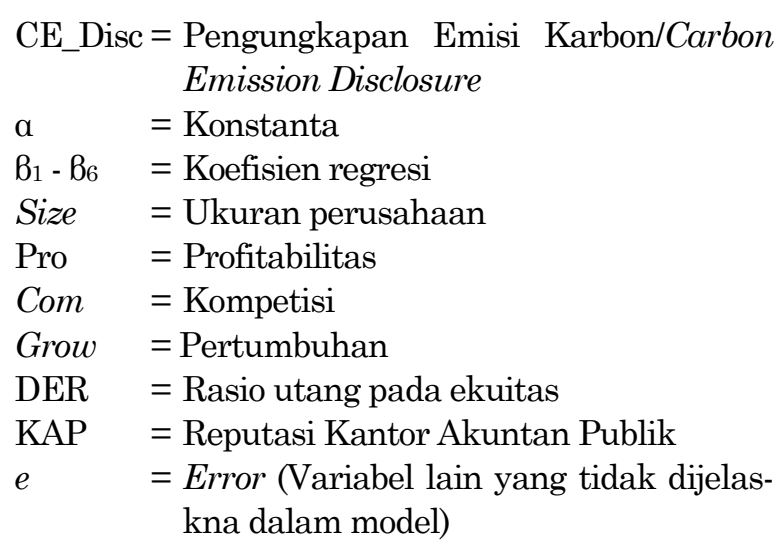

\section{Definisi Operasional Variabel}

Untuk memberikan pemahaman yang lebih spesifik mengenai variabel-variabel penelitian ini, maka variabel tersebut didefinisikan secara operasional disajikan pada tabel 1 .

\section{Penentuan Sampel}

Populasi dari penelitian ini adalah perusahaan manufaktur yang terdaftar di Bursa Efek Indonesia BEI pada tahun 2012-2013. Adapun kriteria sampel yang digunakan yaitu:

1. Perusahaan manufaktur yang telah terdaftar di BEI sejak Januari 2012.

2. Terdaftar di BEI sampai akhir tahun 2013. Sehingga menghasilkan laporan keuangan periode akhir tahun 2013.

3. Menerbitkan laporan keuangan secara lengkap dengan periode pelaporan tahunan yang berakhir pada tanggal 31 Desember.

4. Perusahaan menerbitkan laporan tahunan atau laporan keberlanjutan selama periode 2012 sampai 2013.

5. Perusahaan yang secara eksplisit mengungkapkan emisi karbon (minimal mencakup satu kebijakan terkait dengan emisi karbon/gas rumah kaca atau mengungkapkan minimal satu item pengungkapan emisi karbon). 
Tabel 1. Definisi Operasional Variabel

\begin{tabular}{|c|c|}
\hline Variabel & Definisi dan Pengukuran \\
\hline $\begin{array}{l}\text { 1. Pengungkapan emisi } \\
\text { karbon } \\
\text { (CE_Disc) }\end{array}$ & $\begin{array}{l}\text { Pengungkapan Emisi Karbon adalah luas pengungkapan emisi karbon. Choi et al. (2013) } \\
\text { Memberikan skor pada setiap item pengungkapan (Carbon Emissin } \\
\text { Disclosure Checklist) dengan skala dikotomi. Skor maksimal sebesar 18, } \\
\text { sedangkan skor minimal adalah 0. Setiap item bernilai } 1 \text { sehingga } \\
\text { apabila perusahaan mengungkapkan secara penuh item di dalam } \\
\text { laporanya maka skor perusahaan tersebut sebesar 18, kemudian } \\
\text { menjumlahkan skor setiap perusahaan. Item pengungkapan emisi } \\
\text { karbon ditampilkan pada tabel } 2 \text {. }\end{array}$ \\
\hline $\begin{array}{l}\text { 2. Ukuran perusahaan } \\
\text { (Size) }\end{array}$ & $\begin{array}{l}\text { Ukuran perusahaan adalah logaritma natural (ln) total aset. Rumusnya Stanny dan Ely } \\
\text { sebagai berikut: } \\
\text { Total Asetjt = Logaritman natural total aset perusahaan j tahun } \mathrm{t}\end{array}$ \\
\hline $\begin{array}{l}\text { 3. Profitabilitas } \\
\text { (Pro) }\end{array}$ & $\begin{array}{l}\text { Profitabilitas adalah rasio return on asset ROA. Laba perusahaan dibagi Jannah dan Muid } \\
\text { dengan total aset. Rumusnya sebagai berikut: } \\
\frac{\text { Laba }_{j \mathrm{t}}}{\text { Total Aset }_{\mathrm{jt}}} \\
\text { Labajt } \quad=\text { Laba perusahaan } \mathrm{j} \text { tahun } \mathrm{t} \\
\text { Total Aset }{ }_{j \mathrm{t}}=\text { Total aset perusahaan } \mathrm{j} \text { tahun } \mathrm{t}\end{array}$ \\
\hline $\begin{array}{l}\text { 4. Kompetisi } \\
(\text { Com })\end{array}$ & $\begin{array}{l}\text { Kompetisi adalah Nilai Herfindahl-Hirschman Index. Rumusnya } \\
\text { sebagai berikut: } \\
\sum_{i=1}^{\mathrm{n}}\left[\mathrm{S}_{\mathrm{jt}} / \mathrm{S}_{\mathrm{t}}\right]^{2} \\
\mathrm{~S}_{\mathrm{jt}} \quad=\text { Nilai penjualan perusahaan } \mathrm{j} \text { tahun } \mathrm{t} \\
\mathrm{S}_{\mathrm{t}} \quad=\text { Total penjualan semua perusahaan manufaktur pada tahun } \mathrm{t} \\
\mathrm{S}_{\mathrm{j} t} \mathrm{~S}_{\mathrm{t}}=\text { Pangsa pasar perusahaan } \mathrm{j} \text { tahun } \mathrm{t} \\
\mathrm{n} \quad=\text { Jumlah perusahaan di dalam industri manufaktur }\end{array}$ \\
\hline $\begin{array}{l}\text { 5. Pertumbuhan } \\
(\text { Grow })\end{array}$ & $\begin{array}{l}\text { Laba adalah laba tahun berjalan dibagi dengan laba empat tahun lalu Luo et al. }(2013) \\
\text { dikurangi satu. Rumusnya sebagai berikut: } \\
\frac{\text { Laba tahun berjalan }_{\mathrm{jt}}}{\text { Laba }_{\mathrm{j}} 4 \text { tahun lalu }-1} \\
\text { Laba tahun berjalan } \\
\text { Labaj } 4 \text { tahun lalu- } 1=\text { Laba tahun berjalan perusahaan } \mathrm{j} \text { tahun } \mathrm{t}\end{array}$ \\
\hline $\begin{array}{l}\text { 6. Rasio utang pada } \\
\text { ekuitas } \\
\text { (DER) }\end{array}$ & $\begin{array}{l}\text { Rasio utang pada ekuitas adalah total utang dibagi dengan total ekuitas. D'Amico et al. } \\
\text { Rumusnya sebagai berikut: } \\
\text { DER }=\frac{\text { Total utang }}{\text { Total }_{\mathrm{jt}}} \\
\text { Tokuitas } \\
\text { Total utang } \\
\text { Total }=\text { Total }\end{array}$ \\
\hline $\begin{array}{l}\text { 7. Reputasi Kantor } \\
\text { Akuntan Publik } \\
\text { (KAP) }\end{array}$ & $\begin{array}{l}\text { Reputasi Kantor Akuntan Publik adalah Kantor Akuntan Publik yang Zorio et al. (2013) } \\
\text { memberikan opini pada laporan keuangan perusahaan. } \\
\text { Reputasi Kantor Akuntan Publik diukur dengan menggunakan variabel } \\
\text { dummy. Jika perusahaan diaudit oleh kantor akuntan Big Four } \\
\text { (PricewaterhouseCooper, KPMG, Ernst \& Young dan Deloite) akan } \\
\text { dinilai 1, dan akan dinilai } 0 \text { untuk selain Big Four. }\end{array}$ \\
\hline
\end{tabular}


Tabel 2. Carbon Emissin Disclosure Checklist

\begin{tabular}{|c|c|c|}
\hline Kategori & Item & Keterangan \\
\hline \multirow[t]{2}{*}{$\begin{array}{l}\text { Perubahan iklim: Risiko dan } \\
\text { peluang }\end{array}$} & $\mathrm{CC} 1$ & $\begin{array}{l}\text { Penilaian/deskripsi terhadap risiko (peraturan/regulasi baik khusus } \\
\text { maupun umum) yang berkaitan dengan perubahan iklim dan tindakan } \\
\text { yang diambil untuk mengelola risiko tersebut. }\end{array}$ \\
\hline & $\mathrm{CC} 2$ & $\begin{array}{l}\text { Penilaian/deskripsi saat ini (dan masa depan) dari implikasi keuangan, } \\
\text { bisnis dan peluang dari perubahan iklim. }\end{array}$ \\
\hline \multirow[t]{7}{*}{$\begin{array}{l}\text { Emisi Gas Rumah Kaca } \\
\text { (GHG/Greenhouse Gas) }\end{array}$} & GHG1 & $\begin{array}{l}\text { Deskripsi metodologi yang digunakan untuk menghitung emisi gas rumah } \\
\text { kaca (misal protocol GRK atau ISO). }\end{array}$ \\
\hline & GHG2 & $\begin{array}{l}\text { Keberadaan verifikasi eksternal terhadap penghitungan kuantitas emisi } \\
\text { GRK oleh siapa dan atas dasar apa. }\end{array}$ \\
\hline & GHG3 & Total emisi gas rumah kaca (metrik ton $\mathrm{CO}_{2}$-e) yang dihasilkan. \\
\hline & GHG4 & Pengungkapan lingkup 1 dan 2 , atau 3 emisi GRK langsung. \\
\hline & GHG5 & $\begin{array}{l}\text { Pengungkapan emisi GRK berdasarkan asal atau sumbernya (misal: batu } \\
\text { bara, listrik, dll.). }\end{array}$ \\
\hline & GHG6 & Pengungkapan emisi GRK menurut fasilitas atau tingkat segmen. \\
\hline & GHG7 & Perbandingan emisi GRK dengan tahun-tahun sebelumnya. \\
\hline \multirow{3}{*}{$\begin{array}{l}\text { Konsumsi Energi } \\
\text { (EC/Energy Consumption) }\end{array}$} & EC1 & Jumlah energi yang dikonsumsi (misalnya tera-joule atau Peta-joule). \\
\hline & EC2 & $\begin{array}{l}\text { Penghitungan energi yang digunakan dari sumber daya yang dapat } \\
\text { diperbaharui. }\end{array}$ \\
\hline & EC3 & Pengungkapan menurut jenis, fasilitas atau segmen. \\
\hline \multirow{4}{*}{$\begin{array}{l}\text { Pengurangan Gas Rumah Kaca } \\
\text { dan Biaya (RC/Reduction and } \\
\text { Cost) }\end{array}$} & $\mathrm{RC} 1$ & Perincian dari rencana atau strategi untuk mengurangi emisi GRK. \\
\hline & $\mathrm{RC} 2$ & $\begin{array}{l}\text { Perincian dari tingkat target pengurangan emisi GRK saat ini dan target } \\
\text { pengurangan emisi. }\end{array}$ \\
\hline & RC3 & $\begin{array}{l}\text { Pengurangan emisi dan biaya atau tabungan (costs or savings) yang } \\
\text { dicapai saat ini sebagai akibat dari rencana pengurangan emisi. }\end{array}$ \\
\hline & $\mathrm{RC} 4$ & $\begin{array}{l}\text { Biaya emisi masa depan yang diperhitungkan dalam perencanaan belanja } \\
\text { modal (capital expenditure planning). }\end{array}$ \\
\hline \multirow{2}{*}{$\begin{array}{l}\text { Akuntabilitas Emisi Karbon } \\
\text { (AEC/Accountability of Emission } \\
\text { Carbon) }\end{array}$} & ACC1 & $\begin{array}{l}\text { Indikasi bahwa dewan komite (atau badan eksekutif lainnya) memiliki } \\
\text { tanggung atas tindakan yang berkaitan dengan perubahan iklim. }\end{array}$ \\
\hline & ACC2 & $\begin{array}{l}\text { Deskripsi mekanisme bahwa dewan (atau badan eksekutif lainnya) } \\
\text { meninjau perkembangan perusahaan yang berhubungan dengan } \\
\text { perubahan iklim. }\end{array}$ \\
\hline
\end{tabular}

Sumber: Choi et al. (2013)

\section{HASIL PENELITIAN DAN PEMBAHASAN}

\section{Gambaran Sampel Penelitian}

Obyek dalam penelitian ini adalah perusahaan manufaktur yang terdaftar di Bursa Efek Indonesia (BEI) pada periode 2012-2013. Pemillihan sampel pada penelitian ini menggunakan metode purposive sampling. Berdasarkan metode tersebut diperoleh 19 perusahaan manufaktur yang masuk dalam kriteria sampel. Rangkuman hasil pengambilan sampel ditunjukan pada tabel 3.

Jumlah perusahaan yang terpilih menjadi sampel penelitian sebanyak 19 perusahaan. Jumlah tersebut cukup sedikit, hal ini dapat disebabkan karena Indonesia masih merupakan negara berkembang yang tidak diwajibkan untuk melakukan penurunan emisi GRK sehingga berdampak pada luasnya informasi emisi karbon yang dimiliki perusahaan Indonesia. Disamping itu tujuan pereduksian emisi perusahaan Indonesia hanya untuk menjembatani negara maju dalam memenuhi kewajiban penurunan emisi GRK mereka, dan pengungkapan informasi pada laporan keberlanjutan sementara ini masih bersifat sukarela khususnya informasi pengungkapan emisi karbon.

Tabel 3. Populasi dan Sampel Penelitian Tahun 20122013

\begin{tabular}{lc}
\hline \multicolumn{1}{c}{ Kriteria Sampel } & Jumlah \\
\hline $\begin{array}{l}\text { Total perusahaan manufaktur yang } \\
\text { mempublikasikan Annual Report maupun }\end{array}$ & 132 \\
Sustainability Report pada tahun 2012 dan & \\
2013 & \\
\hline $\begin{array}{l}\text { Total perusahaan yang tidak } \\
\text { mengungkapkan informasi emisi karbon atau } \\
\text { emisi Gas Rumah Kaca pada Annual Report } \\
\text { maupun Sustainability Report }\end{array}$ \\
\hline Sampel perusahaan berdasarkan Kriteria \\
\hline
\end{tabular}


Tabel 4. Descriptive Statistics

\begin{tabular}{|c|c|c|c|c|c|}
\hline Variabel & Maksimum & Rata-rata & Median & Range & Minimum \\
\hline Ukuran perusahaan (X1) & 32,997 & 29,593 & 29,360 & 5,857 & 27,140 \\
\hline Profitabilitas (X2) & 0,404 & $-1,463$ & 0,035 & 58,885 & $-58,482$ \\
\hline Kompetisi (X3) & $3.438,552$ & 181,746 & 2,010 & $3.438,552$ & 0,000 \\
\hline Pertumbuhan (X4) & $23.014,668$ & 598,325 & 0,976 & $23.337,237$ & $-322,569$ \\
\hline Rasio utang pada ekuitas (X5) & 5,063 & 1,625 & 1,410 & 4,905 & 0,158 \\
\hline Reputasi Kantor Akuntan Publik (X6) & 1 & 0,605 & 1 & 1 & 0 \\
\hline Pengungkapan emisi karbon $(\mathrm{Y})$ & 15 & 3,947 & 2 & 14 & \\
\hline
\end{tabular}

Tabel 5. Asumsi Klasik Faktor-Faktor Penentu Pengugkapan Emisi Karbon

\begin{tabular}{lcl}
\hline \multicolumn{1}{c}{ Uji Asumsi } & $\begin{array}{c}\text { Pengungkapan Emisi } \\
\text { Karbon (Y) }\end{array}$ & Hasil \\
\hline Uji Normalitas & 0,783 & $\begin{array}{l}\text { Data residual terdistribusi normal dan tidak } \\
\text { terjadi normalitas }\end{array}$ \\
Kolmogorov-Smirnov Z & 0,571 & \\
Asymp. Sig (2-tailed) & 1,000 & $\begin{array}{l}\text { Data residual adalah acak dan tidak terjadi } \\
\text { autokorelasi }\end{array}$ \\
\hline Autokorelasi & & Variance residual dari pengamatan ke \\
Run Test & $0,762(0,452)$ & pengamatan lainya tetap dan tidak terjadi \\
Heterokedastisitas (t hitung/Sign) & $1,164(0,253)$ & heterokedastisitas \\
Ukuran Perusahaan (X1) & $-1,729(0,094)$ & \\
Profitabilitas (X2) & $-1,029(0,311)$ & \\
Kompetisi (X3) & $-1,413(0,168)$ & \\
Pertumbuhan (X4) & $0,944(0,353)$ & \\
Rasio Utang pada Ekuitas (X5) & & Variabel independen satu dengan independen \\
Kantor Akuntan Publik (X6) & & lainya tidak saling berkorelasi dan tidak \\
Multikolinieritas & 0,529 & terjadi multikolinieritas \\
1. Tolerance (TOL) & 0,894 & \\
Ukuran Perusahaan (X1) & 0,675 & \\
Profitabilitas (X2) & 0,802 & \\
Kompetisi (X3) & 0,909 & \\
Pertumbuhan (X4) & 0,778 & \\
Rasio Utang pada Ekuitas (X5) & & \\
Kantor Akuntan Publik (X6) & 1,891 & \\
\hline 2. Variance Inflation Factor (VIF) & 1,118 & \\
Ukuran Perusahaan (X1) & 1,480 & \\
Profitabilitas (X2) & 1,247 & \\
Kompetisi (X3) & 1,101 & \\
Pertumbuhan (X4) & 1,286 & \\
Rasio Utang pda Ekuitas (X5) & & \\
Kantor Akuntan Publik (X6) & & \\
\hline & & \\
& &
\end{tabular}

\section{Deskripsi Variabel}

Tabel 4 menunjukan rangkuman statistik selama tahun 2012-2013. Variabel-variabel independen dari faktor-faktor penentu pengungkapan emisi karbon ditunjukan oleh hasil nilai rata-rata (mean) dan nilai tengah (median) yang berada di dalam kurung. Rata-rata dan (median) variabel ukuran perusahaan sebesar 29,593 (29,360), angka ini menunjukkan bahwa perusahaan manufaktur yang menjadi sampel penelitian memiliki ukuran yang cukup besar. Sementara itu nilai range yaitu perbedaan jarak antara maksimum dengan minimum relatif kecil, sebesar 5,857.

Profitabilitas sebesar -1,463 (0,035). Angka ini menunjukan perusahaan yang mendapatkan laba lebih besar dibandingkan perusahaan yang meng- alami kerugian, dengan jarak antara maksimum dengan minimum yang relatif rendah, yaitu sebesar 58,885. Kompetisi sebesar 181,746 (2,010). Angka ini menunjukan bahwa posisi relatif perusahaan-perusahaan dalam usaha penyediaan barang-barang masih belum tersebar secara merata. Derajat penyebaran juga sangat tidak merata yang ditunjukan dengan jarak antara maksimum dengan minimum yang relatif tinggi, sebesar 3.438,552. Pertumbuhan sebesar 598,325 (0,976). Angka ini menunjukan bahwa perolehan laba perusahaan-perusahaan meningkat dibandingkan tiga tahun terakhir. Sementara nilai range yaitu perbedaan jarak antara maksimum dengan minimum relatif tinggi, sebesar 23.337,237. Rasio utang pada ekuitas sebesar 1,625 (1,401). Angka ini menunjukan bahwa pendanaan 
perusahaan-perusahaan didominasi oleh utang. Sementara rasio terendah sebesar 0,158 yang berarti perusahaan memiliki kapabilitas sangat baik untuk memenuhi kewajibannya apabila telah jatuh tempo. Variabel terakhir yaitu reputasi Kantor Akuntan Publik menunjukan nilai sebesar 0,605 (1). Angka ini dapat diartikan bahwa perusahaan yang menjadi sampel penelitian ini lebih banyak yang diaudit oleh auditor Big Four. Pengungkapan emisi karbon dari laporan tahunan dan laporan keberlanjutan yang diteliti ditunjukan dalam bentuk nilai rata-rata dan nilai tengah didalam kurung sebesar 3,947 (2). Angka ini dapat diartikan bahwa rata-rata perusahaan mengungkapkan 4 item dari total 18 item berdasarkan pada indeks Carbon Disclosure Project (CDP).

\section{Uji Asumsi Klasik}

Hasil uji asumsi klasik dapat dilihat pada tabel 5. Uji normalitas dengan menggunakan Kolmogorof Smirnov Test menunjukan bahwa nilai probabilitas $(0,571)$ lebih besar dari 0,05 yang artinya data terdistribusi normal. Uji autokorelasi dengan menggunakan Run Test diperoleh nilai signifikansi $(1,000)$ lebih dari 0,05 yang artinya data telah terdistribusi secara acak. Uji heterokedastisitas dengan menggunakan uji glejser menghasilkan sign lebih besar dari 0,05 terhadap absolut residual (absut) pada semua faktor yang artinya tidak terdapat heterokedastisitas. Uji multikolinieritas menunjuakn nilai TOL lebih besar dari 0,10 dan nilai VIF lebih kecil dari 10 yang artinya yang artinya diantara variabel independen tidak saling berkorelasi dan tidak terjadi multikolinieritas.

\section{Pembahasan Hasil Penelitian}

Pengujian dilakukan dengan menggunakan analisis regresi linier berganda. Gambaran hasil regresi lebih jelasnya akan ditampilkan pada tabel 6.

Tabel 6. Hasil Uji Hipotesis

\begin{tabular}{lrr}
\hline \multicolumn{1}{c}{ Variabel } & $\begin{array}{r}\text { Unstandardized } \\
\text { Coefficients (B) }\end{array}$ & $\begin{array}{c}\text { Nilai } \\
\text { Signifikansi } \\
(\mathrm{\alpha}=10 \%)\end{array}$ \\
\hline (Constant) & $-16,178$ &, 209 \\
Ukuran perusahaan &, 701 &, 115 \\
Profitabilitas &, 055 &, 307 \\
Kompetisi &, 000 &, 770 \\
Pertumbuhan & $-9,961 \mathrm{E}-005$ &, 491 \\
Rasio utang pada & $-1,008$ &, 014 \\
ekuitas & &, 101 \\
Reputasi Kantor & 1,850 &, 105 \\
Akuntan Publik & &
\end{tabular}

Dari hasil perhitungan di atas, dapat disimpulkan bahwa dari enam (6) faktor penentu pengungkapan emisi karbon, satu variabel menghasilkan pengaruh signifikan negatif. Variabel tersebut adalah rasio utang pada ekuitas. Sementara lima variabel lainnya, yaitu ukuran perusahaan, profitabilitas, kompetisi, pertumbuhan, dan reputasi kantor akuntan publik tidak menunjukan pengaruh signifikan. Berdasarkan tabel 5 , disimpulkan persamaan matematis sebagai berikut:

$$
\begin{aligned}
\text { CE_Disc }= & -16,178+0,701 \text { Size }+0,055 \text { Pro + } \\
& 0,00 \text { Com }-9,961 \mathrm{E}-005 \text { Grow - } \\
& \text { 1,008DER }+1,850 \mathrm{KAP}+e
\end{aligned}
$$

Berdasarkan hasil penelitian, ukuran perusahaan tidak berpengaruh signifikan positif terhadap pengungkapan emisi karbon. Koefisien yang dihasilkan pada ukuran perusahaan sebesar 0,701 dengan probabilitas 0,115 . Hal ini dapat dikatakan bahwa ukuran perusahaan tidak berpengaruh pada pengungkapan emisi karbon sehingga hipotesis H1 ditolak. Dengan demikian tidak mendukung hasil penelitian, Stanny dan Ely (2008), Prado-Lorenzo et al. (2009), Luo et al. (2010), Tang dan Luo (2011), Gallego-Álvarez (2010), Borghei-Ghomi dan Leung (2013), Choi et al. (2013), Eleftheriadis dan Anagnostopoulou (2014), dan Jannah dan Muid (2014) yang menemukan bahwa ukuran perusahaan berpengaruh signifikan positif pada pengungkapan emisi karbon. Hasil penelitian memberikan kesan bahwa pengungkapan emisi karbon berbeda dengan pengungkapan tanggung jawab sosial (Corporate Social Responsibility). Seperti yang dinyatakan Elkington (1997) bahwa pilar dasar bisnis terdiri dari laba perusahaan (profit), lingkungan (planet) dan masyarakat (people) ditujukan kepada masyarakat, sementara pengungkapan emisi karbon ditujukan kepada pelestarian lingkungan. Pengungkapan tanggung jawab sosial (CSR) ditujukan kepada masyarakat (people), sementara pengungkapan emisi karbon ditujukan kepada usaha mengurangi dampak perubahan iklim melalui reduksi emisi. Sehingga dapat dikatan pengungkapan emisi karbon bertujuan memelihara lingkungan (planet). Selain itu, Pengungkapan tanggung jawab sosial merupakan tanggung jawab perusahaan kepada pemerintah sesuai dengan Undang-Undang No. 40 Tahun 2007 mengenai tanggung jawab sosial dan lingkungan perseroan terbatas. Sementara pengungkapan emisi karbon merupakan pemenuhan tanggung jawab perusahaan yang mereduksi karbon kepada perusahaan yang melakukan investasi sesuai dengan project desain document (PDD). Project desain document adalah dokumen yang berisikan aktifitas yang berkaitan dengan pengurangan emisi 
seperti tujuan proyek, metodologi yang digunakan, estimasi jangka waktu proyek, bagaimana mengukur GHG yang direduksi, pengaruh proyek pada lingkungan, sumber pendanaan, komentar para pemangku kepentingan, rencana monitoring, dan penghitungan aktivitas pengurangan emisi (United Nations Framework Convention on Climate Change (UNFCCC), 2001).

Profitabilitas tidak berpengaruh signifikan positif terhadap pengungkapan emisi karbon. Hasil analisis menunjukan koefisien yang dihasilkan pada profitabilitas sebesar 0,055 dengan probabilitas sebesar 0,307 . Sehingga dapat dikatakan bahwa hipotesis H2 ditolak. Hasil penelitian ini tidak mendukung penelitian Choi et al. (2013), Jannah dan Muid (2014), yang menyatakan bahwa profitabilitas berpengaruh positif terhadap pengungkapan emisi karbon. Hasil penelitian ini menemukan bahwa besarnya profitabilitas tidak bergerak seiring dengan pengungkapan emisi karbon. Hal tersebut dapat disebabkan oleh antara keuntungan dan biaya pengungkapan tidak relevan. Ketika perusahaan mengungkapkan emisi karbon tetapi pengungkapan tersebut membuat investor dan pihak yang berkepentingan menjadi sulit memahami maka pengungkapan ini berkontribusi kecil. Namun bagi perusahan yang menjalankan proyek pengurangan emisi seperti CDM (Clean Development Mechanisme), profitabilitas yang dicapai perusahaan lebih masuk akal ketika dibandingkan dengan luasnya pengungkapan karena pengungkapan tersebut akan mudah dipahami oleh investor dan pihak-pihak terkait dengan proyek pengurangan emisi.

Kompetisi tidak berpengaruh signifikan positif terhadap pengungkapan emisi karbon. Hasil analisis menunjukan nilai koefisisen kompetisi sebesar 0,000 dengan probabilitas 0,770. Dengan demikian, dapat dikatakan bahwa hipotesis H3 ditolak. Hasil penenilitia ini tidak sama dengan penelitian Peng et al. (2014) yang menemukan bahwa kompetisi berpengaruh signifikan positif pada pengungkapan emisi karbon. Hasil ini mengesankan bahwa meskipun perusahaan memiliki pangsa pasar lebih luas, bukan berarti bahwa perusahaan tersebut lebih luas pengungkapannya pada emisi karbon. Perusahaan lebih cenderung menilai risiko perubahan iklim dan strategi mengurangi emisi gas rumah kaca. Nampaknya perusahaan ingin menciptakan persepsi bahwa perusahaan peduli dengan keberlanjutan lingkungan. Sehingga perusahaan yang dinilai peduli lingkungan berarti menciptakan produk ramah lingkungan. Kesempatan ini dimanfaatkan perusahaan untuk memperluas konsentrasi pasar dengan mengajak konsumen ikut serta dalam menjaga lingkungan melalui penggunaan produk ramah lingkungan. Akan tetapi perhatian konsumen tidak akan menggambarkan jumlah jejak karbon. Penelitian ini membuktikan sedikit sekali jumlah perusahaan yang mengungkapkan total gas rumah kaca dan metode yang digunakan untuk mengukurnya. Dengan demikian hasil penelitian menegaskan bahwa tingkat kompetisi mampu memengaruhi perusahaan mengurangi emisi gas rumah kaca karena terkait dengan efisiensi, dan ingin menciptakan image positif, tetapi kompetisi tidak dapat memengaruhi luasnya pengungkapan emisi karbon.

Pertumbuhan tidak berpengaruh signifikan negatif terhadap pengungkapan emisi karbon. Hasil analisis menunjukan nilai koefisien pertumbuhan sebesar -9,961E-005 dengan probabilitas 0,491 . Hasil ini membuktikan bahwa hipotesis H4 ditolak. Sehingga hasil penelitian tidak sama dengan Luo et al. (2013). Perbedaan dengan penelitian sebelumnya dikarenakan ada perusahaan labanya meroket tajam namun sedikit pengungkapan, dan ada perusahaan labanya menurun tapi lebih luas pengungkapannya. Sehingga luas pengungkapan tidak bergerak seiring dengan pertumbuhan. Hal ini dapat disebabkan oleh perusahaan yang tumbuh tinggi akan menghadapi risiko litigasi dan biaya lingkungan ketika perusahaan bertindak tidak sesuai dengan norma yang ditetapkan. Untuk mengatasinya perlu meningkatkan kinerja lingkungan. Akan tetapi, pencapaian kinerja lingkungan akan terhambat jka tidak didukung oleh kinerja perusahaan karena memperluas pengungkapan lingkungan akan mempengaruhi aliran kas secara langsung. Dengan demikian, perusahaan yang mengalami partumbuhan tapi kinerjanya terhambat karena kinerja lingkungan tidak berbeda dengan perusahaan yang mengalami penurunan kinerja.

Rasio utang pada ekuitas menunjukan pengaruh negatif dan signifikan terhadap pengungkapan emisi karbon. Hasil analisis menunjukan nilai koefisen dari rasio utang pada ekuitas menunjukkan nilai -1,008 dengan probabilitas 0,014. Dengan demikian, pengaruh negatif dan signifikan yang dihasilkan dari rasio utang atas modal menunjukkan bahwa hipotesis H5 ditolak. Hasil penelitian ini sejalan dengan Cormier dan Magnan (2003). Hasil penelitian menunjukan bahwa komposisi ekuitas lebih menentukan pengungkapan emisi karbon dibandingkan jumlah utang perusahaan. Walaupun kreditur dan investor samasama membutuhkan informasi pengungkapan potensi risiko akibat perubahan iklim, tetapi pengungkapan emisi karbon lebih ditujukan kepada investor. Hal ini karena, sesuai dengan mekanisme Protokol Kyoto bahwa kewajiban mengurangi emisi gas rumah kaca oleh negara 
maju dapat alihkan ke negara berkembang melalui pendanaan. Perusahaan yang mereduksi emisi sesungguhnya dihadapkan pada risiko ketidakpastian, bahkan akan lebih tinggi risikonya bagi negara berkembang. Untuk mengatasi hal tersebut negara Annex 1 berupaya menyediakan pasar, memberikan jaminan kepada perusahaan yang mereduksi emisi bahwa kredit yang dihasilkan dari aktivitas pengurangan emisi akan dihargai. Mekanisme tersebut menjembatani negara maju mencapai target penurunan emisi yang telah ditetapkan. Selain itu besarnya rasio utang pada ekuitas yang berlainan arah dengan besarnya pengungkapan emisi karbon dapat diasumsikan bahwa perusahaan yang mereduksi emisi sedang berusaha meningkatkan nilai perusahaan agar menjadi tujuan investasi.

Reputasi Kantor Akuntan Publik menunjukkan pengaruh tidak signifikan positif terhadap pengungkapan emisi karbon. Hasil analisis menunjukkan koefisien reputasi Kantor Akuntan Publik sebesar 1,850 dengan probabilitas 0,101. Dengan demikian, hipotesis H6 terkait pengaruh reputasi Kantor Akuntan Publik terhadap pengungkapan emisi karbon ditolak. Temuan ini dikarenakan Kantor akuntan publik indonesia dari kelompok Big Four maupun lainya bukan termasuk lembaga independen yang berhak melakukan penilaian (verifikasi dan validasi) emisi karbon. Penilaian jejak karbon dilakukan oleh badan independen terakreditasi yaitu Designated Operational Entity (DOE). Perusahaan perlu mengeluarkan biaya tinggi untuk mendatangkannya dari luar negeri karena hingga saat ini di Indonesia masih belum ada. Dengan demikian, pertimbangan biaya dan manfaat pengungkapan karbon akan memberikan dampak besar bagi keuangan perusahaan yang pada akhirnya mempengaruhi luasnya pengungkapan.

Perbedaan hasil penelitian in dengan hasil penelitian sebelumnya disebabkan sampel perusahaan yang digunakan di dalam penelitian. Perusahaan mengungkapkan emisi karbon karena perusahaan tersebut memiliki informasi terkait emisi, dan melakukan aktivitas pereduksian emisi yang merupakan bagian dari usaha bersama-sama untuk mencapai batas emisi yang telah menjadi komitmen saat negara asalnya meratifikasi Protokol Kyoto. Jadi walaupun pengungkapan emisi merupakan pengungkapan sukarela, tetapi pemilihan sampel akan berpengaruh pada hasil penelitian.

Secara garis besar hasil penelitian ini menunjukkan bahwa perusahaan yang mereduksi emisi karbon memiliki nilai ekuitas lebih besar dari pada nilai utang. Lebih besarnya nilai ekuitas dibanding nilai utang pada komposisi modal perusahaan emisi rendah menandakan bahwa perusahaan telah didukung oleh masyarakat secara finansial. Perolehan dukungan dana akan memaksimalkan kekuatan jangka panjang pada sisi keuangan dan selanjutnya meningkatkan kepastian perusahaan untuk melanjutkan usahanya. Berdasarkan uraian tersebut, maka pengungkapan emisi karbon dapat diartikan berhasil menyebabkan perusahaan memperoleh legitimasi dari masyarakat melalui dukungan pada sisi keuangan yang ditandai dengan lebih besarnya nilai ekuitas dari pada nilai utang pada perusahaan beremisi rendah.

\section{KESIMPULAN DAN SARAN}

Faktor-faktor yang diuji didalam penelitian ini terkait pengaruhnya terhadap pengungkapan emisi karbon (Carbon emission Disclosure) pada perusahaan manufaktur Indonesia meliputi ukuran perusahaan, profitabilitas, kompetisi, partumbuhan, rasio utang pada ekuitas, reputasi Kantor Akuntan Publik. Berdasarkan pada hasil pengujian, hanya Rasio utang pada ekuitas berpengaruh negatif signifikan. Sementara faktor lainnya tidak berpengaruh signifikan terhadap pengungkapan emisi karbon di Indonesia.

Penelitian ini memiliki keterbatasan yang dapat dijadikan bahan pertimbangan bagi peneliti berikutnya. Pertama, Metode penelitian yang digunakan berupa indeks yang dikembangkan oleh (Choi et al. (2013)) berdasarkan pada lembar permintaan yang didapatkan dari Carbon Disclosure Project (CDP) versi 2009. Kedua, Penelitian ini menggunakan laporan tahunan dan laporan keberlanjutan perusahaan dalam mengukur luas pengungkapan emisi karbon. Akibatnya sampel penelitian memiliki kemampuan generalisasi rendah karena perusahaan yang tidak terdaftar pada UNFCCC memiliki informasi sedikit tentang emisi gasnya. Ketiga, metode penilaian memberikan skor 1 pada setiap item jika terdapat informasi pengungkapan. Sehingga apabila perusahaan mengungkapkan semua item yang berjumlah 18, maka skor maksimal yang diperoleh perusahaan sebesar 18.

Dengan adanya keterbatasan tersebut diharapkan penelitian selanjutnya dapat memperbaiki keterbatasan penelitian ini. Pertama, peneliti selanjutnya diharapkan mampu mengembangkan cecklist berdasarkan pada kuesioner Carbon Disclosure Project (CDP) yang lebih baru. Kedua, menggunakan sampel perusahaan yang telah melakukan skema pembangunan besih (CDM) atau dapat membandingkan perusahaan yang melakukan skema pembangunan besih (CDM) dengan yang tidak. Ketiga, memberikan skor sebesar jumlah informasi yang diungkapkan 
terkait dengan item. Pemberian skor tidak dibatasi, sehingga total skor maksimal yang dapat diperoleh tergantung seberapa banyak jumlah informasi yang diungkapkan.

Implikasi penelitian ini pertama, penelitian ini dapat digunakan sebagai saran dalam berinvestasi yakni agar berinvestasi pada perusahaan yang lebih peduli pada lingkungan demi menjaga kelestarian alam. Sebab masalah perubahan iklim, pemanasan global telah menjadi isu yang semakin meluas dan menarik reaksi tingkat internasional. Sehingga dengan memprioritaskan investasi pada perusahaan ramah lingkungan artinya ikut peduli terhadap alam. Kedua, untuk lembaga pendanaan agar lebih mendukung, memberikan kemudahan, insentif kepada perusahaan yang lebih berusaha menjaga dan memperbaiki kualitas lingkungan. Dengan mendukung mereka maka cara pandang debitur akan berubah dalam mencapai target pelunasan utang. Mereka akan terdorong lebih peduli terhadap kelestarian lingkungan sehingga upaya dalam pengembalian pinjaman dengan mengabaikan keberlanjutan dapat dirubah bersama-sama. Pada akhirnya keseimbangan antara tiga pilar dasar bisnis yang meliputi profit, people, dan planet tercapai.

\section{DAFTAR PUSTAKA}

Ahmad, Z., Hassan, S., and Mohammad, J. 2003. Determinants of environmental reporting in Malaysia. International Journal of Business Studies, 11(1), 69.

Borghei-Ghomi, Z., and Leung, P. 2013. An Empirical Analysis of the Determinants of Greenhouse Gas Voluntary Disclosure in Australia. Accounting and Finance Research, 2(1), p110.

Choi, B.B., Lee, D., and Psaros, J. 2013. An Analysis of Australian Company Carbon Emission Disclosures. Pacific Accounting Review, 25(1), 58-79.

Cormier, D., and Magnan, M. 2003. Environmental Reporting Management: a Continental European Perspective. Journal of Accounting and public Policy, 22(1), 43-62.

Craswell, A.T., and Taylor, S.L. 1992. Discretionary disclosure of reserves by oil and gas companies: an economic analysis. Journal of Business Finance \& Accounting, 19(2), 295308.

D'Amico, E., Coluccia, D., Fontana, S., and Solimene, S. 2014. Factors Influencing Corporate Environmental Disclosure. Business Strategy and the Environment.

Deegan, C., Rankin, M., and Tobin, J. 2002. An examination of the corporate social and environmental disclosures of BHP from 1983-
1997: A test of legitimacy theory. Accounting, Auditing \& Accountability Journal, 15(3), 312-343.

, and Unerman, J. 2006. Financial Accounting Theory: McGraw-Hill Education Maidenhead.

Eleftheriadis, I.M., and Anagnostopoulou, E.G. 2014. Relationship Between Corporate Climate Change Disclosures and Firm Factors. Business Strategy and the Environment.

Elkington, J. 1997. Cannibals with Forks The Triple Bottom Line of 21st Century Business. Oxford: Capstone Publishing Limited.

Freedman, M., and Jaggi, B. 2005. Global Warming, Commitment to the Kyoto Protocol, and Accounting Disclosures by the Largest Global Public Firms from Polluting Industries. The International Journal of Accounting, 40(3), 215-232.

Gallego-Álvarez, I. 2010. Indicators for Sustainable Development: Relationship between Indicators Related to Climate Change and Explanatory Factors. Sustainable Development, 20(4), 276-292.

Ghozali, I., and Chariri, A. 2007. Teori Akuntansi (Vol. 3). Semarang: Badan Penerbit Universitas Diponegoro

Gray, R., Owen, D., and Adams, C. 1996. Accounting \& Accountability: Changes and Challenges in Corporate Social and Environmental Reporting: Prentice Hall.

Horváthová, E. 2010. Does environmental performance affect financial performance? A metaanalysis. Ecological Economics, 70(1), 52-59.

Jannah, R., and Muid, D. 2014. Analisis FaktorFaktor yang Mempengaruhi Carbon Emission Disclosure pada Perusahaan di Indonesia (Studi Empiris pada Perusahaan yang Terdaftar di Bursa Efek Indonesia Periode 20102012).

Long, X., Naminse, E.Y., Du, J., and Zhuang, J. 2015. Nonrenewable energy, renewable energy, carbon dioxide emissions and economic growth in China from 1952 to 2012. Renewable and Sustainable Energy Reviews, 52, 680688.

Luo, L., Lan, Y.-C., and Tang, Q. 2010. Corporate Incentives to Disclose Carbon Information: Evidence from Global 500. SSRN 1725106.

, Tang, Q., and Lan, Y.-C. 2013. Comparison of Propensity for Carbon Disclosure between Developing and Developed Countries: A Resource Constraint Perspective. Accounting Research Journal, 26(1), 6-34.

March, J. G. 1981. Decisions in organizations and theories of choice. Perspectives on organization design and behavior, 205, 44. 
Peng, J., Sun, J., and Luo, R. 2014. Corporate Voluntary Carbon Information Disclosure: Evidence from China's Listed Companies. The World Economy, 38(1), 91-109.

Prado-Lorenzo, J.-M., Rodríguez-Domínguez, L., Gallego-Álvarez, I., and García-Sánchez, I.-M. 2009. Factors Influencing the Disclosure of Greenhouse Gas Emissions in Companies World-Wide. Management Decision, 47(7), 1133-1157.

Ratnatunga, J. 2007. Carbon Cost Accounting: The Impact of Global Warming on the Cost Accounting Profession. Journal of applied management accounting research, 5(2).

Roberts, R.W. 1992. Determinants of corporate social responsibility disclosure: An application of stakeholder theory. Accounting, Organizations and Society, 17(6), 595-612.

Sartono, A. 2001. Manajemen Keuangan "Teori dan Aplikasi. Yogyakarta: BPFE.

Stanny, E., and Ely, K. 2008. Corporate Environmental Disclosures about the Effects of Climate Change. Corporate Social Responsibility and Environmental Management, 15(6), 338-348.

Tang, Q., and Luo, L. 2011. Transparency of Corporate Carbon Disclosure: International Evidence. SSRN 1885230.
Titman, S., and Trueman, B. 1986. Information quality and the valuation of new issues. Journal of Accounting and economics, 8(2), 159-172.

United Nations Framework Convention on Climate Change (UNFCCC). 1998. Kyoto Protocol to The United Nations Framework Convention on Climate Change.

. 2001. Report of the Conference of the Parties on its seventh session, held at Marrakesh from 29 October to 10 November 2001 Addendum part two: Action taken by the Conference of the Parties (Vol. 2, pp. 43). . 2012. Doha Amendment to the Kyoto Protocol.

Watts, R.L., and Zimmerman, J.L. 1986. Positive accounting theory.

Zhao, R., and Zhong, S. 2015. Carbon labelling influences on consumers' behaviour: A system dynamics approach. Ecological Indicators, 51, 98-106.

Zorio, A., García-Benau, M.A., and Sierra, L. 2013. Sustainability Development and the Quality of Assurance Reports: Empirical Evidence. Business Strategy and the Environment, 22(7), 484-500. doi: 10.1002/bse.1764 